\title{
EFFECT OF MCKENZIE EXERCISES ON FUNCTIONAL NECK DISABILITY IN FEMALES WITH DOWAGER'S HUMP
}

Nadia A. Abd Elmeged *; Amaal H.M. Ibrahim** ; Awatef M. Labib ***; Adel R. Ahmed ****;

\section{Ghada I. Mohamed ****** and Heba A. Kamal ******}

* Researcher of physical therapy for Basic Science Department,Faculty of physical Therapy,ElKasr ElAiny, Cairo University.

**Professor of physical therapy ,Basic Science Department, Faculty of physical Therapy ,Cairo University

*** Professor of physical therapy ,Basic Science Department, Faculty of physical Therapy ,Cairo University

**** Professor of physical therapy ,Basic Science Department, Faculty of physical Therapy, Cairo University

*****Assistant professor of physical therapy ,Basic Science Department, Faculty of physical Therapy ,Cairo University.

******Professor of Radiodiagnosis ,Faculty of Medicine Elkasr Elainy ,Cairo University .

*E-mail - Dr.nadiasalem91@yahoo.com

\section{ABSTRACT}

Background : : Dowager`s hump is a faulty habitual posture alignment of the cervical spine, where in the head is positioned anterior to the shoulder. Prolonged forward head posture (FHP) leads to the development of hump, predominantly seen in menopaused females.Objective : This study was conducted to investigate the effect of Mckenzie exercises on females with Dowager's hump in cervical region - Methods : Thirty female patients with Dowager's hump aged from 3859 years randomly distributed to 2 equal groups. The treatment was applied 3 times per week for 8 weeks .Pain intensity level and neck functional ability were measured pre-treatment and post 8 weeks of tratment. Group A (control ) : 15 female patient received conventional physiotherapy and Group B (study ) include 15 female patient received conventional therapy in addition to Mckenzie exercises. The treatment was applied 3 times per week for 8 weeks .Pain intensity level and neck functional ability were measured pre-treatment and post-tratment.

Results: the study group showed statistical significance reduction in pain intensity level and neck disability index more than control group .

Conclusion : Mckenzie exercises improves neck functional ability and pain level intensity in females patients with Dowager's hump in cervical . Key words :Mckenzie exercises ,Dowager's hump, NDI, VAS . 


\section{INTRODUCTION}

Dowager's hump is an abnormal outward curvature of the thoracic vertebrae of the upper back. Compression of the front portion of the involved vertebrae due to osteoporosis leads to forward bending of the spine (kyphosis) and creates a hump at the upper back. Like most osteoporotic changes, it is often preventable (Duangkaew et al ., 2020). The prevalence of dowager's hump in older persons is 20 to 40 percent and increases with age (Kado et al., 2013).

Forward head posture(FHP ) can also create dowager's hump, FHP occurs when the head moves forward, the torso moves backward and the hips tip forward to compensate. The natural curve of cervical and lumbar spine becomes less lordotic . Degenerative changes of the cervical spine are commonly accompanied by a reduction or loss of the lordosis and are often considered to be a cause of neck pain (Grob et al., 2007).

Change in the curvature of the neck bone causes upper crossed syndrome, which leads to rounded shoulder posture and shoulder pain . FHP that causes round shoulder and neck pain due to an imbalance between the curvature of the spine and muscles that are attached to the neck bone, is correlated with problems in the neck bone all these will lead to fusion of neck joint which lead to arthritis (Kim and Kim 2016) .

The discs and vertebral bodies become wedged, it progresses to greater sagittal malalignment. This hump can lead to cervical myelopathy due to the curve of the spine (Scheer et al ., 2013 ).

Normal movement patterns were altered by persistent pain, joint fixations, nerve entrapment and protective muscle guarding, new neuronal pathways were burned into her central nervous system (Miranda \& Kage 2020).

Patients with straight and kyphotic cervical curves were 18 times more likely to present with cervicogenic symptoms. The studies found a statistically significant association between cervical pain and lordosis angle of less than 20 degree. (McAviney et al., 2005).

The Neck Disability Index (NDI) is the most widely used and most strongly valid instrument for assessing self -rated disability in patients with neck pain . It has been used effectively in both clinical and research settings in the treatment of the very common problem (Vernon, 2008 ).

A Visual Analogue Scale (VAS) is a measurement instrument that measure a characteristic or attitude that is believed to range across a continuum of values and cannot easily measured. The patient marks on the line the point that they feel represents their perception of their current state (Crichton, 2001).

Neck retraction was first recommended by Stevens and McKenzie to treat cervical pain.It involves pulling the head and neck posteriorly directly over the thorax, while the head and eyes remain at same level. 
Retraction may increase cervical range of motion, improve neck posture ,relieve neck or referred pain, and move the nucleus pulposus to a more anterior position and prevent recurrences of pain (Abdulwahab and Sabbahi., 2000 ).

So there is a gap of knowledge in variety of methods that can correct or treat dowager's hump, Also there is no studies that tried mckenzie exercises as a treatment method for dowager's hump only few studied use postural correction. The aim of this study was to investigate the effect of mckenzie exercises on functional neck ability at female patients with Dowager's hump.

\section{Design, setting ,methods, population}

\section{MATERIALS AND METHODS :}

The study randomized control trial pre-post test design .It performed at out patient clinic in physical therapy department at El KASR ELAINY hospital Cairo Egypt from september 2018 to march 2019 . This study was conducted with the approval \&under supervision of the ethical committee of the faculty of physical therapy, cairo university (P.T.REC/012/001757) in accordance with standards of the Helsinki Declaration . All patients participated in the study signing the approved consent form.

The power of the study was measured post hoc by G*Power 3.1 software. F-test MANOVA within and between interaction effects was selected. With total sample size 30 subjects, type I error (2 tailed) was 0.05 and effect size of 1.13 .

Thirty female patients with age $39-58$ years who met the inclusion criteria and diagnosed by orthopedist as dowager's hump with cervical disc \& neck pain were taken as a sample in the study .

\section{Inclusion criteria :}

1. 30 Female patients at age ( 39 to 58 years mean age of menopause) (Li et al ., 2010) (Mahfouz et al., 2015 ).

2. Female patients referred from physician diagnosis as dowager's hump with neck pain and referred pain at upper limb .

3. Female patients with limited cervical range of motion flexion, extension and side bending .

4. Absolute rotatory angle (cervical lordotic angle ) less than 20 degree who have cervicogenic symptoms ( McAviney et al ., 2005).

5. visual analogue scale used to assess pain level ( Hawker et al ., 2011 ).

6. Neck disability index score as neck pain affect the function of neck at daily living activity ( Sterling \& Rebbeck, 2005). 
7. BMI is within 25- $30 \mathrm{~kg} \operatorname{lm} 2$ (Sheng et al ., 2017) .

\section{Exclusion criteria :}

1. Patients with any neck surgery (chung et al ., 2012 ).

2. Neurological infection and systemic diseases including cerebrovascular disease ,spinal cord injury ,cancer ,ankylosing spondylitis (chung et al ., 2012).

3. Patients with congenital musculoskeletal deformity (Gupta et al .2013 ).

4. Patients with cervical trauma or car accident ( Wani et al ., 2013 ).

5. patients with severe osteoporosis by referral of orthopedist (Ali et al ., 2015 ) .

6. obese patients with BMI more than $30 \mathrm{~kg} / \mathrm{m} 2$.

\section{Procedures :}

A) Assessment Procedures :

1)Visual analogue scale (VAS)

- Pain was measured by Visual Analogue Scale for both groups.

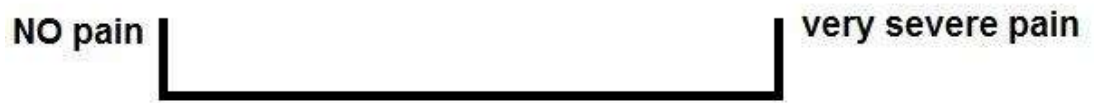

\section{2) Neck disability index (NDI ) :}

NDI is a 10-item questionnaire that measures a patient's selfreported neck pain related disability. Questions include activities of daily living, such as: personal care, lifting, reading, work, driving, sleeping, recreational activities, pain intensity, concentration and headache. Each question is measured on a scale from 0 (no disability) to 5 , and an overall score out of 100 is calculated by adding each item score together and multiplying it by two. A higher NDI score means the greater a patient's perceived disability due to neck pain. (Howell, 2011).

It consists of 10 items each of 10 items each of them is scored from $0-5$. The total maximum score is therefore 50 . The original report provided intervals for interpretation, as $(1-4)=$ no disability, $(5-14)$ $=$ mild,$(15-24)=$ moderate,$(25-34)=$ severe,$($ above 34$)=$ complete disability (Haneline, 2006).

\section{B) Treatment procedures :}

1) Group A (control ) : Included 15 female patients were received conventional physical therapy treatment as ( upper back extension exercise from prone and sitting position , abdominal isomertric 
exercise ,pectoral stretching (Hallal , 1991) ,3 session per week for 8 week.

1) upper back extension exercise from prone. : patient postioned in prone ,both hands grasp behind the lower back then ask patient to raise her head and her shoulder up ward.

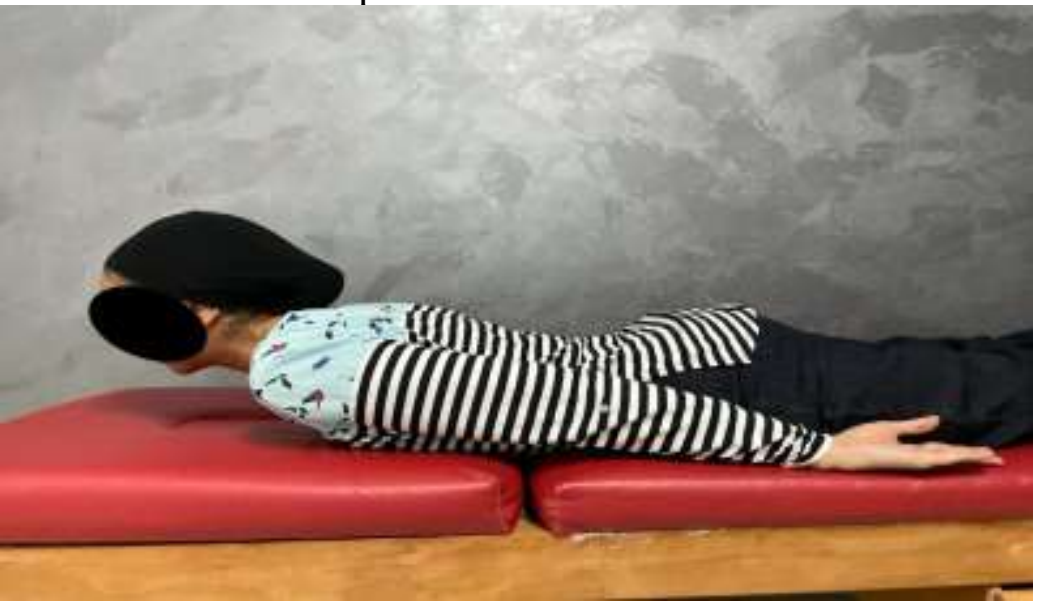

Fig 1: Upper back extension from prone .

2) upper back extension exercise from sitting : Patient in sitting position, both hands behind the patient supported on bed and ask patient to bring her head ,shoulder and upper back backward as much as possible.

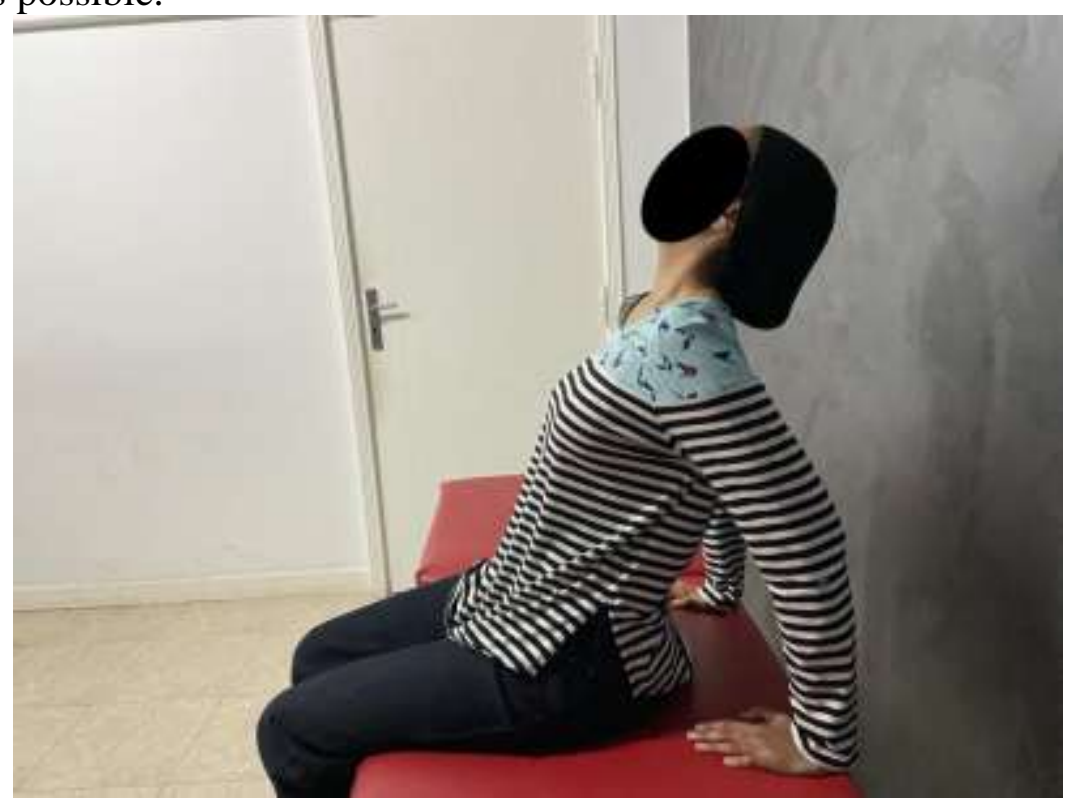

Fig 2 : Upper back extension ex. From sitting • 
3) abdominal isometric exercise :Patient in crock lying position, ask the patient to contract her abdomen and push her lower back (lumber ) to bed downward and relax.

4) ) Pectoral stretch exercise :The patient in sitting position ,ask patient to hold her hands behind the head then therapist pulling both arms backward as much as possible to stretch pectoralis major with the limit of pain

2) Group B (study ) : ): 15 female patients had assigned randomly who received conventional treatment ( upper back extension exercise from prone and sitting ,abdominal isomertric ex,pectoral stretching ex.) in addition to McKenzie exercises 3 sessions per week for 8 weeks as

\section{1)Retraction in supine position :}

This involved the patient lying supine with the head off the treatment table with clinician-applied traction and extension maintained throughout the range of motion to end range .

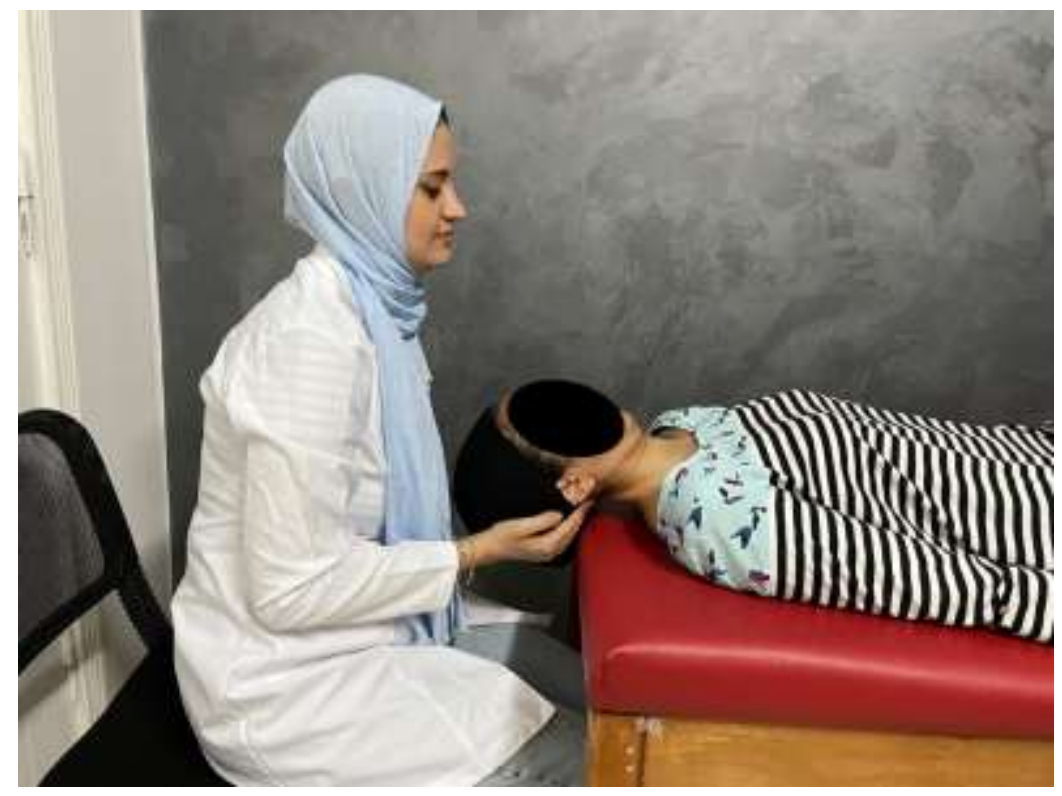

Fig 3: Retraction in supine position

2)Retraction in sitting position : The patients were in a relaxed comfortable sitting position with good back support, the patients then instructed to draw their head as far back as possible, with the head remaining horizontal, facing forward, and not inclining up or down . This was repeated 10 to 15 times and also at home. 


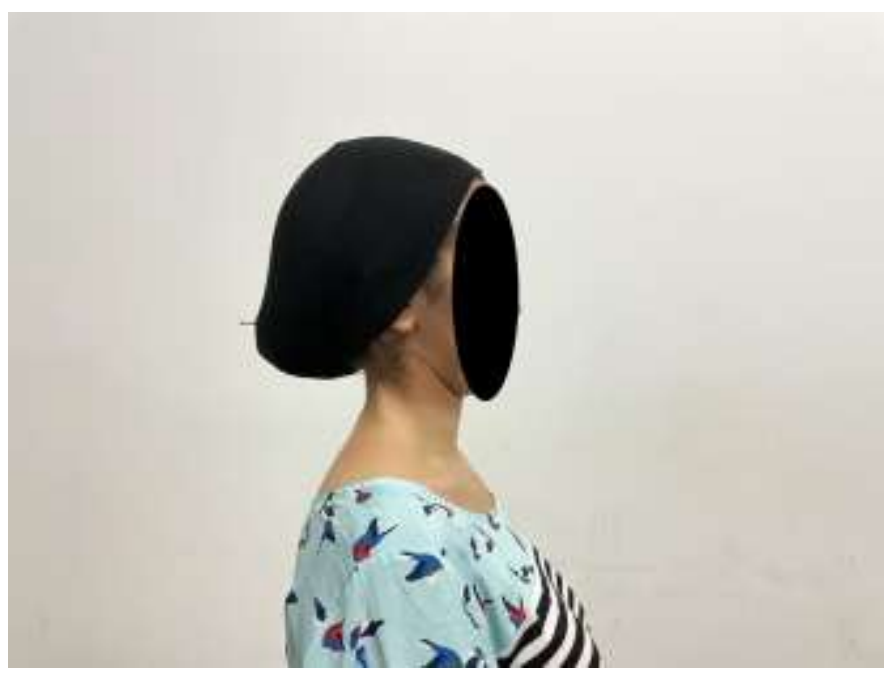

Fig 4 : Chin in ex . in sitting position .

3) Retraction with patient overpressure : The patients returned to the neutral sitting position and instructed to apply overpressure by pressing the chin with their fingers at the end of rang of the movement. This was repeated 10 to 15 times.

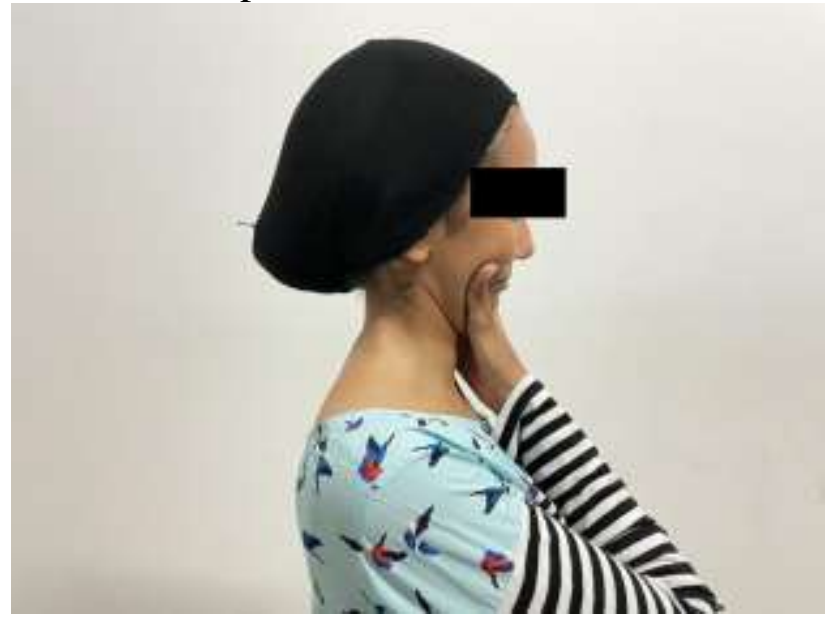

Fig 5 : Chin in with patient overpressure

4 ) Retraction with therapist overpressure : The patients were in a relaxed comfortable sitting position with good back support and the therapist was standing at the side of the patients with the thumb; forefinger of one hand was applied against the patient's mandible and the heel of the other hand at the level of the first or second thoracic vertebrae. The therapist hand on the mandible stabilizes the head at end range of retraction and repeated 5 or 6 times . 


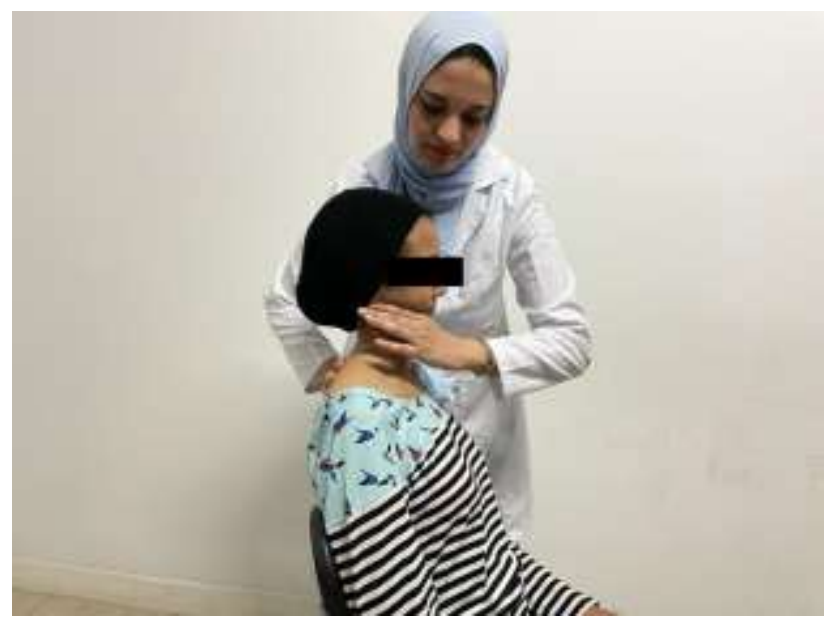

Fig 6 : Chin in with therapist overpressure

5) Retraction with extension : The patients were in a relaxed comfortable sitting position, The patients instructed to draw their heads as far back as possible, with the head remaining horizontal, facing forward, and then instructed to 'bend his head backwards as far as he can to look at the ceiling then returned to the neutral sitting position. The patients were instructed to repeat the movements 10 to 15 times.

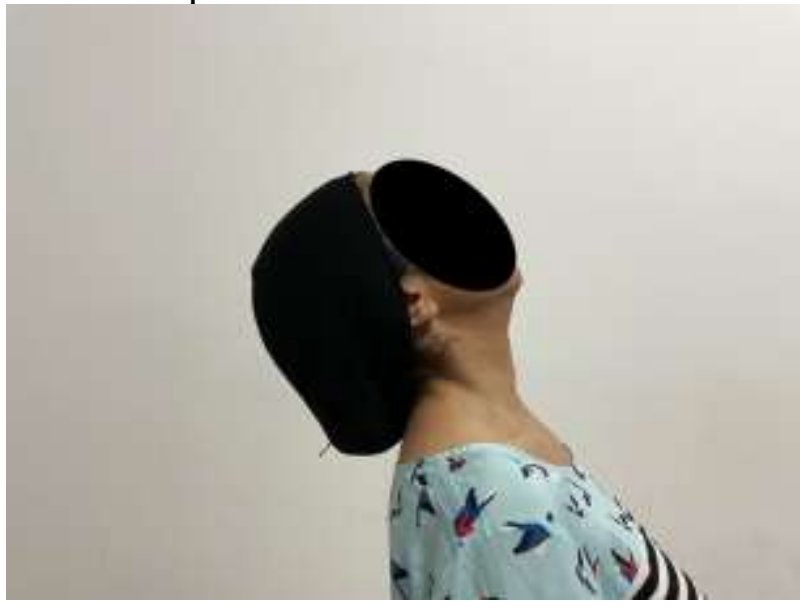

Fig 7 : Chin in with extension

6) Retraction with rotation : The patients were in a relaxed comfortable sitting position. The patients instructed to retract their heads, but not fully, and then rotate the head towards the side of pain: 'Turn as far as you can as if looking over your right- left shoulder'. After a second in that position they were instructed to return to the neutral posture. The same movements were repeated rhythmically 10 to 15 times . 


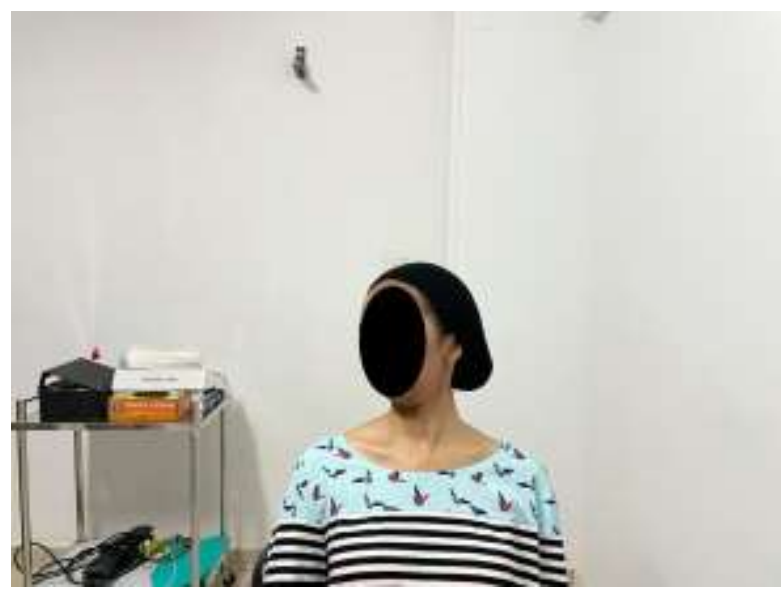

Fig 8 :Chin in with rotation

7) Rotation with patient overpressure : The patients were instructed to repeat the same movements of some retraction followed by active rotation. Then instructed and shown the following against your chin; apply extra pressure so your head is pushed further into rotation.' After a second in that position they were instructed to return to the neutral posture.

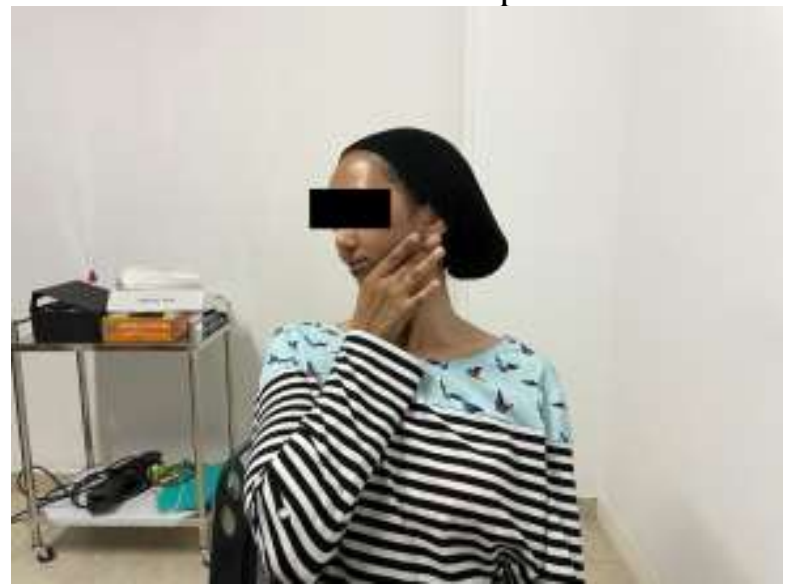

Fig 9: Rotation with patient over pressure

8)Rotation with therapist overpressure : The patients were in a relaxed comfortable sitting with the head in a slightly retracted. The therapist stands behind the patients with his right hand resting lightly on the patient's right trapezius. The therapist carried the patient's head with his left hand. The patient asked to rotate their heads to end of rang at which point the therapist produce a further rotation force using the left arm to rotate the head and the right hand applies a counter - pressure against the spinous process .The movement was repeated five or six times . 


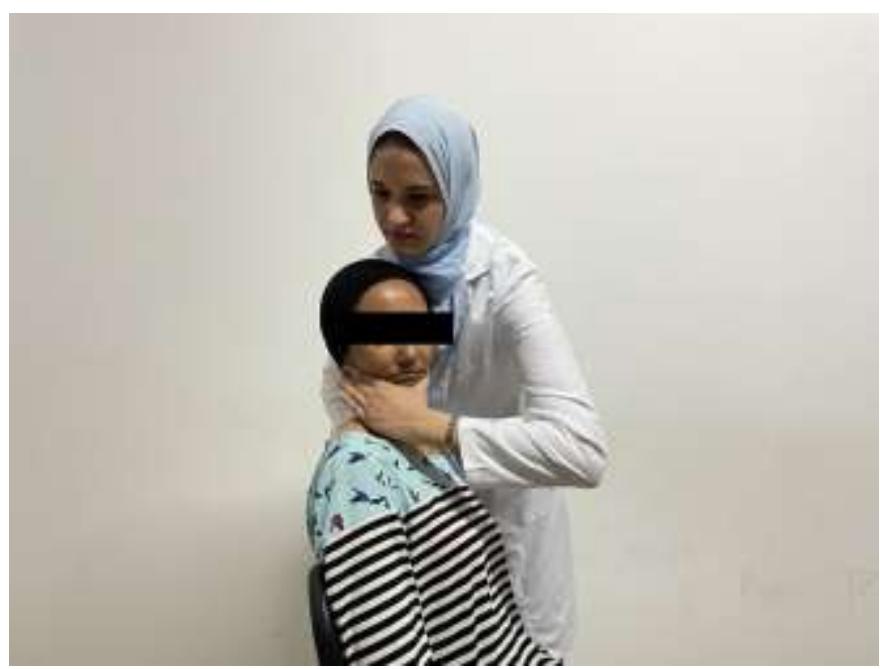

Fig 10 : Rotation with therapist over pressure

9) Lateral flexion:The patients were in a relaxed comfortable sitting position, The patients instructed to retract the head and then lateral flex towards the side of pain: 'Take your right /left ear towards your shoulders, repeated rhythmically 10 to 15 times, returning to the neutral position eatch time.

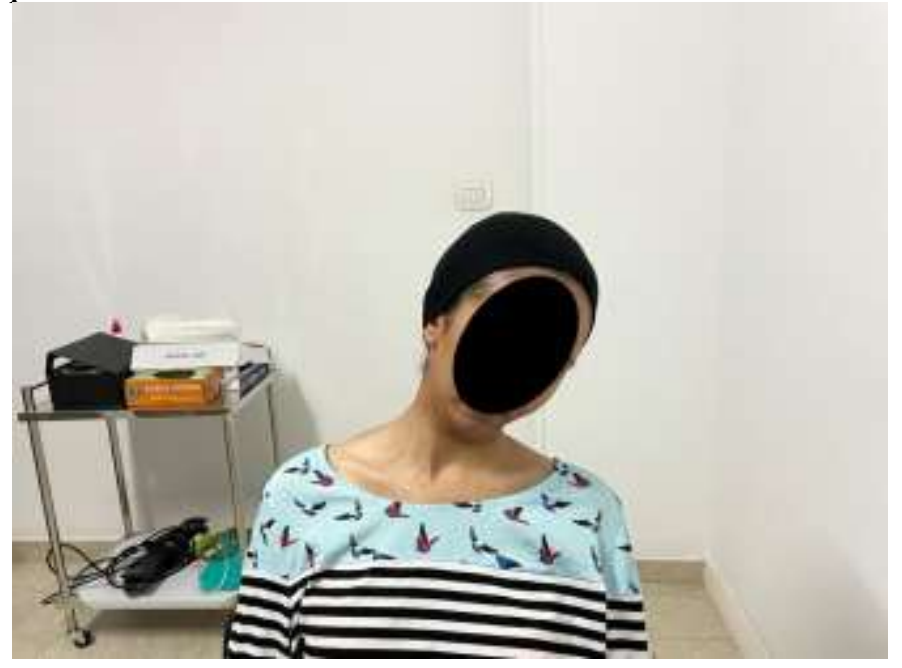

Fig 11 :Chin in with lateral flexion

10) Lateral flexion with patient overpressure: The patients were in a relaxed comfortable sitting position. The patients instructed to retraction followed by active lateral flexion with patient pressure at chin, then they were instructed to return to the upright posture. The same movements were repeated rhythmically 10 to 15 times . 


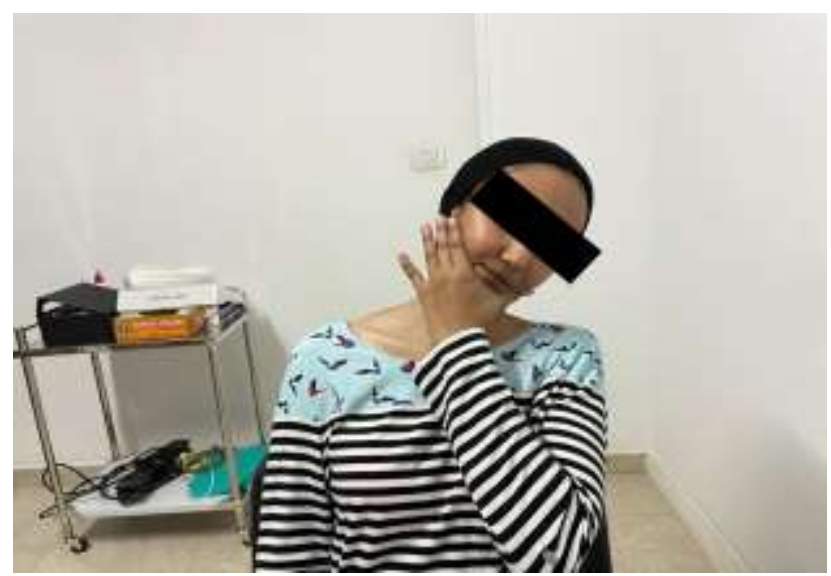

\section{0)Lateral flexion therapist overpressure:}

Fig 12 :Lateral flexion with patient over pressure

The patients were in a relaxed comfortable sitting with the head in a slightly retracted position. The tip of the therapist's thumb rests on the left side of the spinous process of the upper thoracic level and the metatarsophalangeal junction of the index finger of the left hand rests against the lateral aspect of the cervical column at the appropriated level. the forearms of the therapist was positioned parallel to each other the patients were asked to retract slightly and then to lateral flex his head to end range. At the end of the movement the therapist applied downward pressure on the side of the patients head with the right hand and a counter pressure with the thumb on the spinous process. The position held for one or two seconds then the patient returns the head to the upright position the movement is then repeated five to six time .

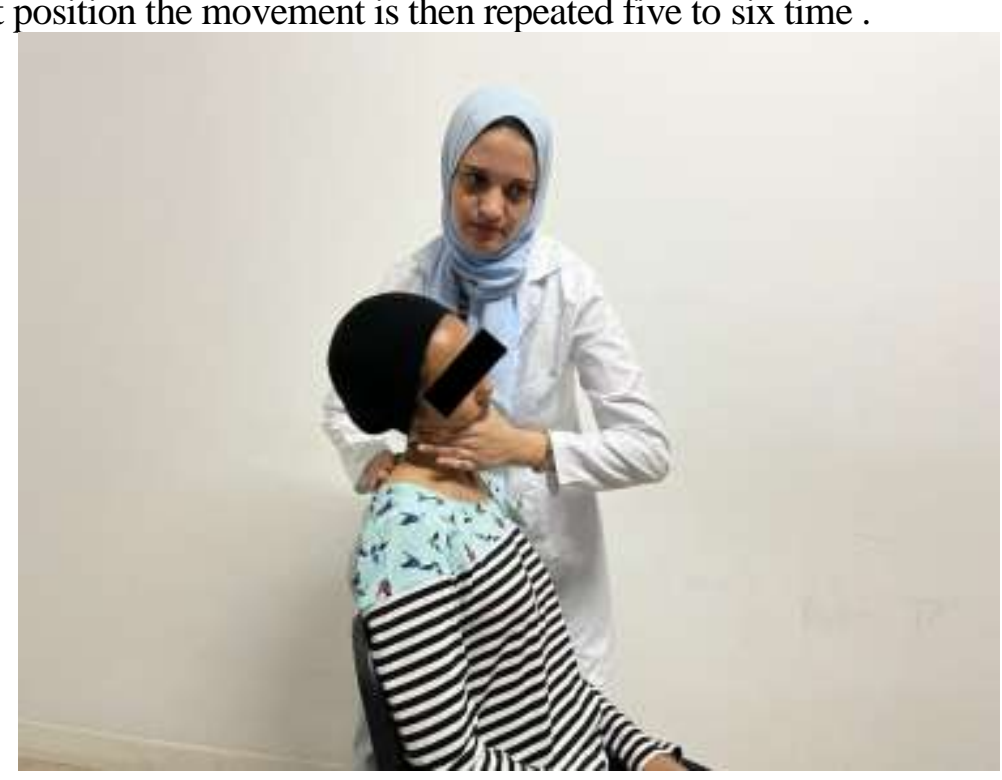

Fig 13 : Lateral flexion with therapist over pressure 


\section{RESULTS}

Statistical analysis was conducted using SPSS for windows, version 18 (SPSS, Inc., Chicago, IL). The current test involved two independent variables. The first one was the (tested group); between subject factor which had two levels (group A receiving traditional treatment, group B receiving conventional treatment \&Mckenzie exercises ). The second one was the (treatment periods as 8 weeks ); within subject factor which had two levels (pre treatment, post treatment). In addition, this test involved two tested dependent variables (NDI and VAS).

Preliminary assumption checking revealed that data was normally distributed for NDI, ARA, VAS, as assessed by Shapiro-Wilk test $(p>0.05)$; there were no univariate or multivariate outliers, as assessed by boxplot and Mahalanobis distance $(p>0.05)$, respectively; there were linear relationships, as assessed by scatterplot; no multicollinearity. There was homogeneity of variances ( $p>0.05)$, as assessed by Levene's test of homogeneity of variances. Accordingly, $2 \times 2$ mixed design MANOVA was used to compare the NDI and VAS at different measuring periods at both groups. The alpha level was set at 0.05 .

Table (1): Physical characteristics of participants in both groups (A\&B).

\begin{tabular}{|c|c|c|c|c|c|}
\hline \multirow[t]{2}{*}{ Items } & \multirow{2}{*}{$\begin{array}{l}\text { Group A } \\
\text { Mean } \pm \text { SD }\end{array}$} & \multirow{2}{*}{$\frac{\text { Group B }}{\text { Mean } \pm \text { SD }}$} & \multicolumn{2}{|c|}{ Comparison } & \multirow{2}{*}{$\mathbf{S}$} \\
\hline & & & t-value & P-value & \\
\hline Age (years) & $46.46 \pm 6.58$ & $46.73 \pm 7.65$ & -0.102 & 0.919 & NS \\
\hline Body mass (Kg) & $79.73 \pm 7.01$ & $78.06 \pm 5.56$ & 0.721 & 0.477 & NS \\
\hline Height (cm) & $164.13 \pm 5.04$ & $165.33 \pm 5.77$ & -0.606 & 0.549 & NS \\
\hline BMI $\left(\mathrm{kg} / \mathrm{m}^{2}\right)$ & $29.02 \pm 3.1$ & $28.68 \pm 2.56$ & 0.324 & 0.749 & NS \\
\hline
\end{tabular}

*SD: standard deviation, P: probability, S: significance, NS: non-significant.

- $\quad$ Neck disability index (NDI) :

Table ( 2 ): Mean \pm SD and $p$ values of NDI pre and post-test at both groups.

\begin{tabular}{|l|l|l|l|l|l|}
\hline \multirow{2}{*}{ NDI } & Pre test & Post test & $\begin{array}{l}\% \text { of } \\
\text { change }\end{array}$ & p- value \\
\hline & Mean \pm SD & Mean \pm SD & & \\
\hline Group A & $30.12 \pm 3.88$ & $30.1 \pm 3.8$ & 0.02 & 0.06 & 0.99 \\
\hline Group B & $30.78 \pm 6.95$ & $18.26 \pm 7.76$ & 12.52 & 40.67 & $0.0001^{*}$ \\
\hline MD & -0.66 & 11.84 & & & \\
\hline p- value & 0.748 & $0.0001^{*}$ & & & \\
\hline
\end{tabular}

*Significant level is set at alpha level $<0.05$ MD: Mean difference

p-value: probability value 
Mean values of NDI Pre and post-study within both groups

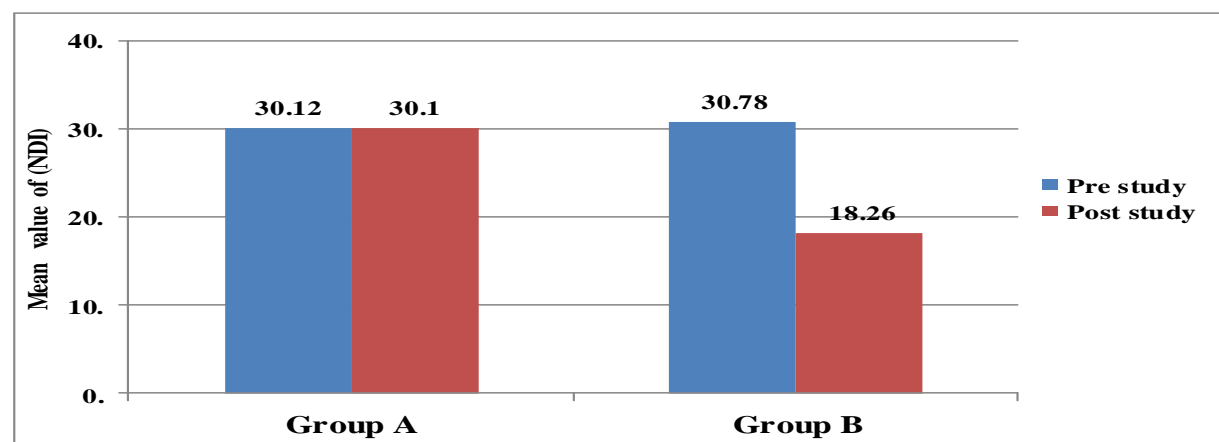

Figure (14 ): Mean values of NDI pre and post study within both groups.

As presented in figure (14) there was no significant difference of $\mathrm{NDI}$ at post treatment in compare to pre-treatment $(\mathrm{P}$-value $=0.99)$ at group (A) while there was significant reduction of NDI at post treatment in compare to pre-treatment $\left(\mathrm{P}\right.$-value $\left.=0.0001^{*}\right)$ at group $(\mathrm{B})$.

Mean values of NDI pre and post-study between two groups

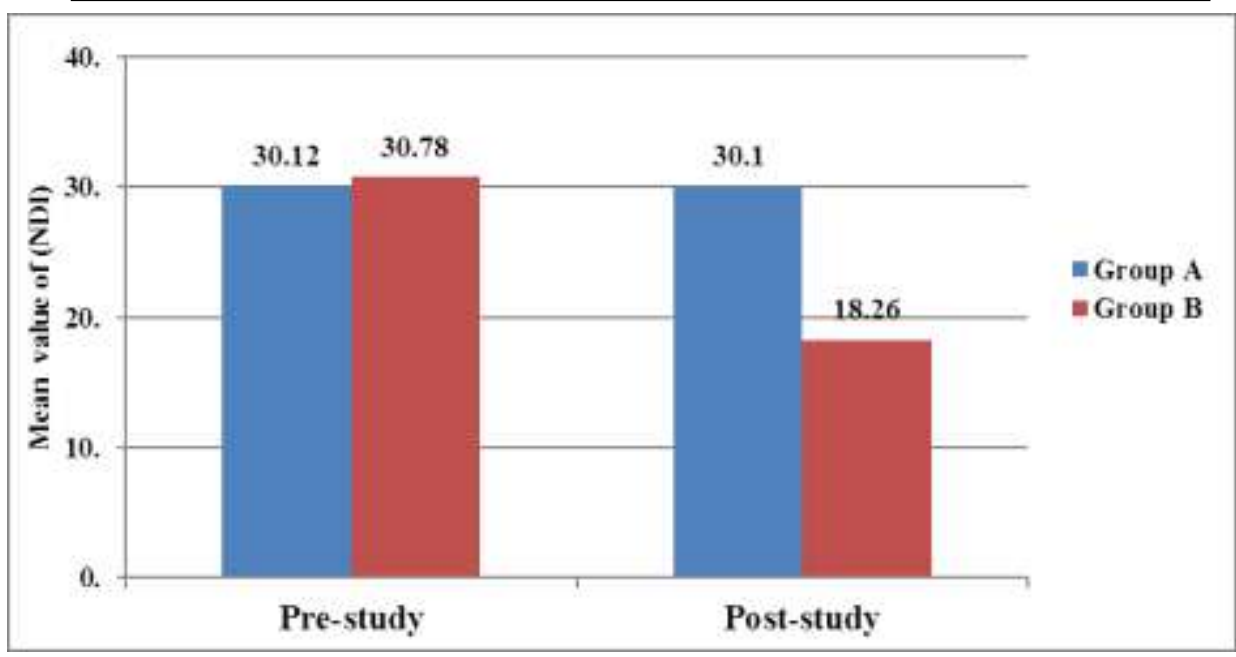

Figure (15): Mean values of NDI pre and post study between both groups.

As well as, multiple pairwise comparison tests (Post hoc tests) revealed that there was significant difference of the mean values of the "post" test between both groups with $\left(\mathrm{p}=0.0001^{*}\right)$ and this significant reduction in favour to group B than group A. 
- Visual analogue scale (VAS):

Table (5 ): Mean \pm SD and $p$ values of VAS pre and post-test at both groups.

\begin{tabular}{|l|l|l|l|l|l|}
\hline \multirow{2}{*}{ VAS } & Pre test & Post test & MD & $\begin{array}{l}\% \text { of } \\
\text { change }\end{array}$ & p- value \\
\hline & Mean \pm SD & Mean \pm SD & & \\
\hline Group A & $8.56 \pm 0.7$ & $3.26 \pm 1.03$ & 5.3 & 61.9 & $0.0001^{*}$ \\
\hline Group B & $8.03 \pm 0.85$ & $8 \pm 0.8$ & 0.03 & 0.3 & 0.99 \\
\hline MD & 0.53 & -4.74 & & & \\
\hline p- value & 0.088 & $0.0001^{*}$ & & & \\
\hline
\end{tabular}

*Significant level is set at alpha level $<0.05$ MD: Mean difference

SD: standard deviation p-value: probability value

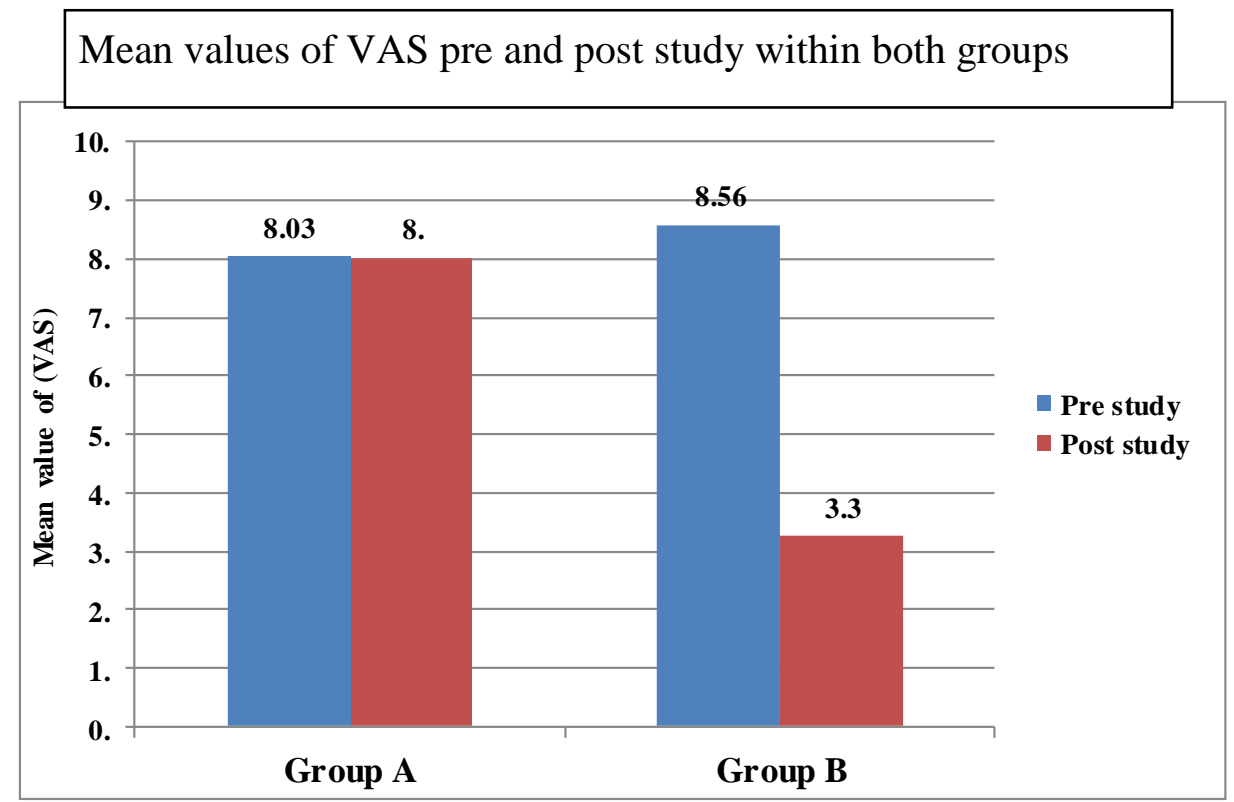

Figure (16): Mean values of VAS pre and post study within both groups

As presented in figure (16) that there was no significant difference of VAS at post treatment in compare to pre-treatment (P-value $=0.99$ ) in group (A). While that there was significant reduction of VAS at post treatment in compare to pre-treatment $\left(\mathrm{P}\right.$-value $\left.=0.0001^{*}\right)$ in group (B) . 


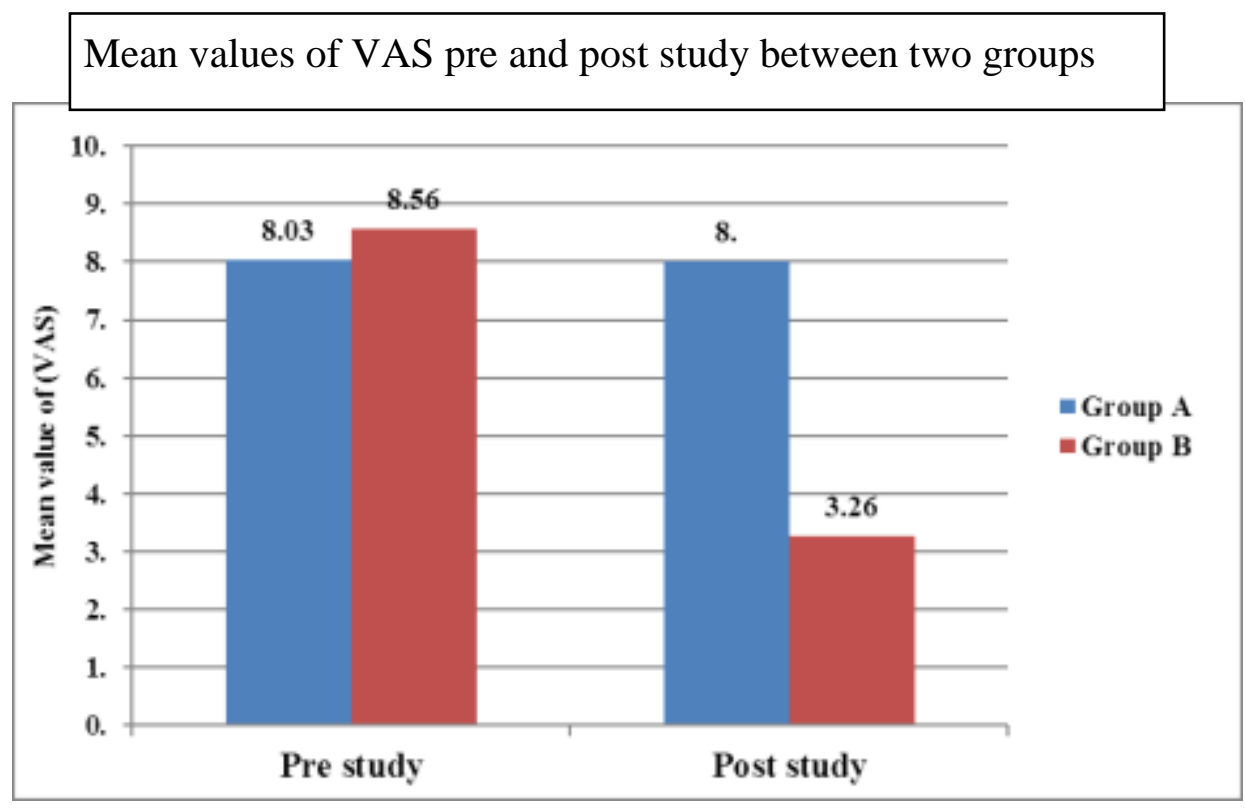

Figure (17): Mean values of VAS pre and post study between both groups

As well as, multiple pairwise comparison tests (Post hoc tests) revealed that there was significant difference of the mean values of the "post" test between both groups with $\left(\mathrm{p}=0.0001^{*}\right)$ and this significant reduction in favour to group $B$ than group A.

\section{DISCUSSION}

The current study was conducted to study the effect of Mckenzie exercises on pain intensity level, absolute rotatory angle and neck functional ability in female patients with dowager's hump in cervical region .

The result of this study revealed that :

That there was no significant difference of NDI at post treatment in compare to pre-treatment at control group while there was significant reduction of NDI at post treatment in compare to pre-treatment at study group .

Also that there was no significant difference of VAS at post treatment in compare to pre-treatment in control group,while showed that there was significant reduction of VAS at post treatment in compare to pre-treatment in study group so Mckenzie exercises had a good and safe effect at dowager's hump by decreasing neck pain and increasing functional neck ability .

The results of the current study are in agreement with Gupta et al ., (2013) who investigated that deep cervical flexor training as chin in exercise appeared to be effective in reducing pain and disability. The reason 
might be that DCF training specifically involved upper cervical flexion action and that majority of subjects suffered from neck pain. DCF training might have directly influenced pain sensitive structures of upper cervical region. Also DCF muscle training is recommended clinically for management of neck pain . This study was conducted in 6 months including 2 groups : experimental (DCF training ) and control (conventional isometric training ) performed at 30 patients each group has 15 patients and treatment period was 4 weeks. This study showed the same results of our study for pain intensity level and NDI .

Our results were supported by the work of Chung et al ., (2012 ) who investigated that retraining of DCF can lead to stabilize the neutral posture of cervical vertebrae, enhance balance and function of cervical vertebrae , which improved the quality of every day life and decrease cervical pain .

The results confirmed by work of Moustafa et al ., (2016) who investigate that McKenzie protocol of treatment had significant improvement in cervical ROM , pain intensity level and neck functional activity level. Also physical performance improved in McKenzie group as a result of enhancement of cognitive and sensory perception of pain and reduce anxiety toward physical activity. There was another reason to reduce pain that was performing repetitive neck retraction in patients with cervical radiclupathy advanced cervical root decompression, diminished radiclupathy pain in lower cervical area. This study had 2 groups each had 15 patients, one group received conventional treatment as (US and strengthening ex.) and study group received conventional plus McKenzie protocol 3 times per week and treatment time last for 6 weeks. Their age ranged from 30 to 50 years old.

These results were in line with Moustafa and Diab ., (2011) who found that strengthening deep cervical flexors through chin tucks in supine along with posture correction exercises significantly reduced pain in cases of lower cervical spondylotic radiculopathy the same for patients of dowager's hump .

Abdulwahab \& Sabbahi ., ( 2000) agreed with the current study, who investigated that neck retraction was first recommended by McKenzie to treat cervical pain. It involves pulling the head and neck posteriorly into a position in which the head is aligned more directly over the thorax, while the head and eyes remain level. .It is believed that neck retraction may increase cervical range of motion, improve resting neck radicular pain, and possibly move the nucleus pulposus to a more anterior position and prevent recurrences of pain.

Similarly Rathore ( 2003) found that Neck retraction, which has been advocated by McKenzie in the treatment of patients with cervical problems causes extension of the lower cervical segments and may alleviate stress on the posterior annulus and thereby relieve pain. In patients with 
neck and radicular pain, repeated neck retraction was shown to result in a significant decrease in peripheral pain and decreased nerve root compression . A positive response to spinal loading would result in lowered pain intensity, centralization of symptoms or an increased range of motion.

Our results were supported by the work of Kim et al ., (2018) who study on the effects of McKenzie exercise on functional recovery and FHP in patients with chronic neck pain, McKenzie exercise led to significant changes of craniovertebral angle and NDI .This study was divided into 3 groups group A underwent McKenzie exercises and myofacial release group $\mathrm{B}$ underwent McKenzie exercises and Kinesio taping, and group C underwent McKenzie exercise, MFR, and Kinesio taping. It was including forward head posture patients with chronic neck pain , treatment period was 4 weeks , 3 sessions per week .The study showed that all three types of interventions improved FHP with chronic neck pain which lead to enhance NDI and posture of neck to shoulder .

In contrast, the study done by Lytras et al ., (2017) found that the VAS, NDI and ROM scores improved equally in both groups,(therapeutic ex and McKenzie ex ) suggests that the McKenzie method is equally effective in improving the clinical presentation of chronic neck pain patients.,but therapeutic exercise seems to be more effective in improving strength of neck muscles than McKenzie exercises.

\section{CONCLUSION :}

Based on the scope and findings of this study, It can be concluded that Mckenzie exercises are safe and effective modality, and resulted in great improvements in pain intensity and functional neck ability in female patients with Dowager"s hump at cervical region .

\section{RECOMMENDATION:}

Further study should be concluded with large number of sample also different age groups, concluded with longer treatment period .

We should try the study at different work related disorder or special jobs like dentists, also different groups of sex (males ) and try different type of exercises .

\section{REFERENCES}

Abdulwahab, S. S. and M. Sabbahi (2000). Neck retractions, cervical root decompression, and radicular pain. Journal of Orthopaedic \& Sports Physical Therapy, 30(1): 4-12.

Ali, M. F. ; S. H. El-Wardany and S. K. Alduraibi (2015). Effect of kinesio taping in patients with mechanical neck dysfunction. Med J Cairo Univ, 83: 867-873 
Chung, S. H. ; J. G. Her ; T. Ko ; Y. Y. You and J. S. Lee (2012). Effects of exercise on deep cervical flexors in patients with chronic neck pain. Journal of Physical Therapy Science, 24(7): 629-632.

Crichton, N. (2001). Visual analogue scale (VAS). J Clin Nurs, 10(5): 706-6.

Duangkaew, R. ; J. Bettany-Saltikov ; P. Van Schaik ; G. Kandasamy and J. Hogg (2020). PROTOCOL: Exercise interventions to improve back shape/posture, balance, falls and fear of falling in older adults with hyperkyphosis: A systematic review. Campbell Systematic Reviews, 16(3): e1101.

Grob, D. ; H. Frauenfelder and A. F. Mannion, (2007). The association between cervical spine curvature and neck pain. European Spine Journal, 16(5): 669-678.

Gupta, B.D. ; S. Aggarwal ; B. Gupta ; M. Gupta and N. Gupta (2013). Effect of deep cervical flexor training vs. conventional isometric training on forward head posture, pain, neck disability index in dentists suffering from chronic neck pain. Journal of clinical and diagnostic research: JCDR, 7(10):, 2261.

Haneline, M.T. (2006): Evidence-based chiropractic practice, 1 st ed. Jones and Bartlett learning, 26(3): 139-51.

Hawker, G. A. ; S. Mian ; T. Kendzerska and M. French (2011). Measures of adult pain: Visual analog scale for pain (vas pain), numeric rating scale for pain (nrs pain), mcgill pain questionnaire (mpq), short-form mcgill pain questionnaire (sf-mpq), chronic pain grade scale (cpgs), short form-36 bodily pain scale (sf-36 bps), and measure of intermittent and constant osteoarthritis pain (icoap). Arthritis care \& research, 63(S11):, S240-S252.

Howell, E. R. (2011). The association between neck pain, the Neck Disability Index and cervical ranges of motion: a narrative review. The Journal of the Canadian Chiropractic Association, 55(3): 211

Kado, D.M. ; K.E. Schmader and D.J. Sullivan (2013). Overview of hyperkyphosis in older persons.

Kim, E. K. and J. S. Kim (2016). Correlation between rounded shoulder posture, neck disability indices, and degree of forward head posture. Journal of physical therapy science, 28(10): 2929-2932.

Kim, J. ; S. Kim ; J. Shim ; H. Kim ; S. Moon ; N. Lee and E. Choi (2018). Effects of McKenzie exercise, Kinesio taping, and myofascial release on the forward head posture. Journal of physical therapy science, 30(8): 1103-1107

Li, S. ; H. He ; M. Ding and C. He (2010). The correlation of osteoporosis to clinical features: a study of 4382 female cases of a hospital cohort with musculoskeletal symptoms in southwest China. BMC Musculoskeletal Disorders, 11(1): 183. 
Lytras, D. ; N. Koulis and E. Sykaras (2017). Comparison of two Exercise Programs in Patients with Chronic Neck Pain.

Mahfouz, E.M. ; N.N. Kamal and E.S. Mohammed (2015). Quantifying diabetes risk and identifying contributing factors among middle aged females in Minia district, Egypt. Intern. J. Healthcare Science, 3(2): 643-652.

McAviney, J. ; D. Schulz ; R. Bock ; D. E. Harrison and B. Holland (2005). Determining the relationship between cervical lordosis and neck complaints. Journal of manipulative and physiological therapeutics, 28(3): 187-193.

Miranda, N. S. and V. Kage (2020). Effect of MaRhyThe versus myofascial mobility tool in female individuals with or without neck pain having forward head posture and buffalo hump-A randomized clinical trial. Indian Journal of Physical Therapy and Research, 2(2): 113

Moustafa, I.M. ; A.A. Diab ; S. Taha and D.E. Harrison (2016). Addition of a sagittal cervical posture corrective orthotic device to a multimodal rehabilitation program improves short-and long-term outcomes in patients with discogenic cervical 73 ra di c ul o pa thy. A rc hive s of p hysi cal me di ci ne a n d rehabilitation, 97(12): 2034-2044

Moustafa, I.; A. Diaab ; A. Ahmed ; D. Harrison and T.M. Shousha (2011). The efHicacy of cervical lordosis rehabilitation for nerve root function, pain, and segmental motion in cervical spondylotic radiculopathy. WCPT

Rathore, S. (2003). Use of McKenzie cervical protocol in the treatment of radicular neck pain in a machine operator. The journal of the Canadian Chiropractic association, 47(4): 291.

Scheer, J.K. ; J.A. Tang ; J.S. Smith ; F.L. Acosta ; T.S. Protopsaltis ; B. Blondel and C.P. Ames (2013). Cervical spine alignment, sagittal deformity, and clinical implications: a review. Journal of Neurosurgery: Spine, 19(2): 141-159.

Sheng, B. ; K. Truong ; H. Spitler ; L. Zhang ; X. Tong and L. Chen (2017). The long-term effects of bariatric surgery on type 2 diabetes remission, microvascular and macrovascular complications, and mortality: a systematic review and metaanalysis. Obesity surgery, 27(10): 2724-2732.

Sterling, M. and T. Rebbeck, (2005). The neck disability index (NDI). Australian Journal of Physiotherapy, 51(4): 271.

Vernon, H. (2008). The Neck Disability Index: state-of-the-art, 19912008. Journal of manipulative and physiological therapeutics, 31(7): 491-502. 
Wani, S. ; N. Raka ; J. Jethwa and R. Mohammed (2013). Comparative efficacy of cervical retraction exercises (McKenzie) with and without using pressure biofeedback in cervical spondylosis. International Journal of Therapy and Rehabilitation, 20(10): 501- 508

\section{تأثير تمارين تقنية ماكنزي على تحدب دواجر للإناث في منطقة الرقبة}

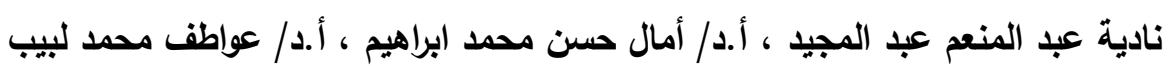

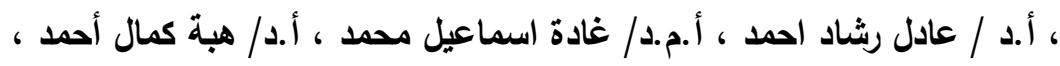

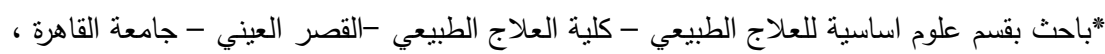

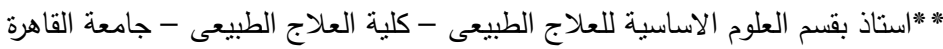

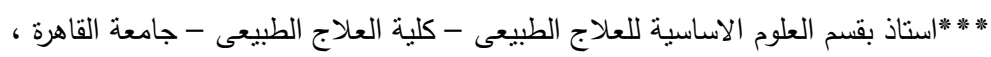

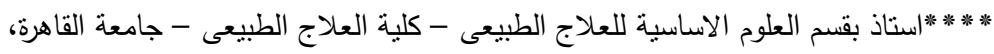
)

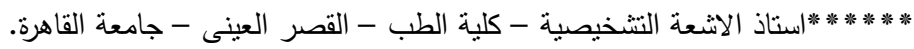

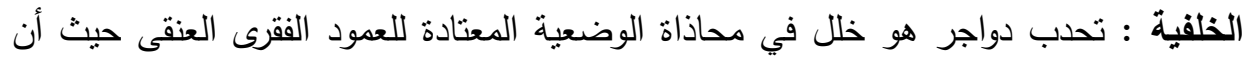

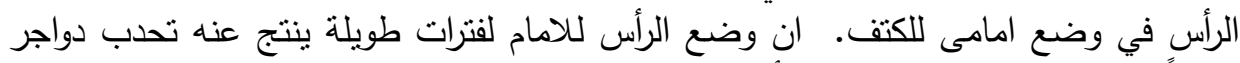

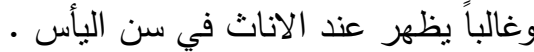

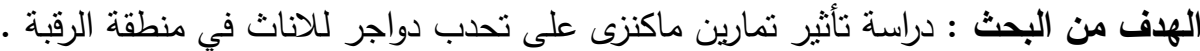

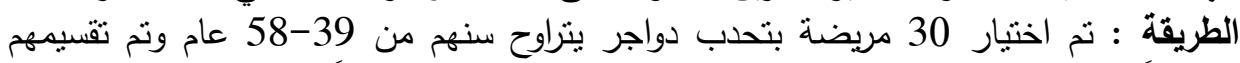

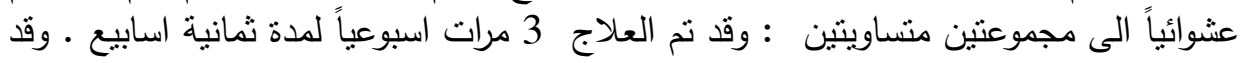

تم قياس معدل شدة الالم ومؤشر العجز الوظيفي قبل اجراء العلاج وبعده بثمانية اسابيع •

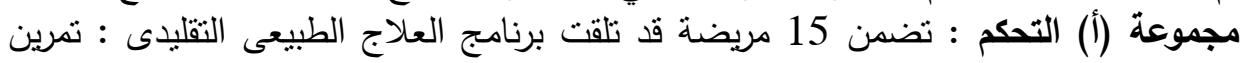
تمديد الظهر العلوى في وضع الجلوس والانبطاح وتمرين البطن متساوى القياس وتمرين الطالة مجموعة (ب) الاراسة : تضمن 15 مريضة تلقت العلاج التقليدى بالاضافة الى تمارين ماكنزى.تم قياس معدل شدة الالم ومؤشر العجز الوظيفي قبل وبعد العلاج . النتائج :

اظهرت مجموعة الدراسة انخفاض احصائي ملحوظ في معدل شدة الالم ومؤشر العجز الوظيفي

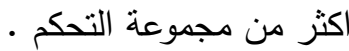

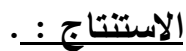

أداء تمارين تقنية ماكنزي يؤدي الي تحسن معدل الالم و القدرة الوظيفية للرقبة في

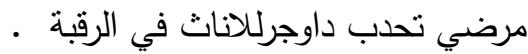

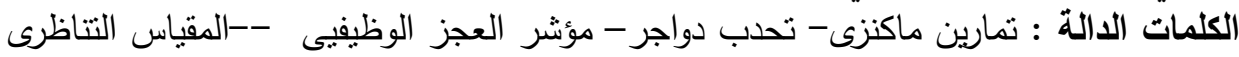

